\title{
ALTERAÇÕES FUNCIONAIS DO FÍGADO APÓS DERIVAÇÃO PORTO-CAVA E HEPATECTOMIA PARCIAL. ESTUDO EXPERIMENTAL EM CÃES
}

\section{LIVER FUNCTION ALTERATIONS AFTER PORTOCAVAL SHUNT AND PARTIAL HEPATECTOMY. EXPERIMENTAL STUDY IN DOGS}

\author{
Valdinaldo Aragão de Melo, TCBC-SE ${ }^{1}$ \\ Reginaldo Ceneviva, TCBC-SP ${ }^{2}$ \\ Álvaro Queiroz de Godoy, TCBC-PR ${ }^{3}$ \\ José Ernesto dos Santos ${ }^{4}$ \\ Gustavo Barreto de Melo 5
}

\begin{abstract}
RESUMO: Objetivo: Estudar os efeitos da derivação porto-cava sobre a função hepática de cães. Método: Vinte animais foram divididos em dois grupos: o Grupo I foi submetido à hepatectomia parcial de 28,7\% e o Grupo II, à hepatectomia parcial associada à derivação porto-cava. Os parâmetros analisados foram: consumo de anestésico durante o ato cirúrgico, dosagem de amônia pré e pós-operatória ( $\left.15^{\circ} \mathrm{e} 30^{\circ} \mathrm{dia}\right)$, AST, bilirrubina total e frações, proteínas totais, albumina e teste de retenção da bromosulfaleína (pré-operatório e $30^{\circ}$ dia do pós-operatório) Resultados: O consumo de anestésico foi significativamente menor no Grupo II. No Grupo I, apenas a AST estava elevada no pós-operatório quando comparada aos valores pré-operatórios. Já no Grupo II, a amonemia estava elevada no $15^{\circ}$ e no $30^{\circ}$ dia do pós-operatório em relação ao pré-operatório e aos mesmos períodos do Grupo I. Todos os outros parâmetros analisados apresentaram-se elevados quando comparados com os valores anteriores à cirurgia e aos do Grupo I, com exceção das proteínas totais e da albumina, que estavam significativamente reduzidas. Conclusões: A derivação porto-cava causa comprometimento importante da função hepática, traduzido por elevação da amônia sanguínea e alteração nas provas funcionais do fígado.
\end{abstract}

Descritores: Derivação porto-cava cirúrgica; Hepatectomia; Fígado; Modelos animais.

\section{INTRODUÇÃO}

A derivação porto-cava foi proposta inicialmente para o tratamento da ascite e para o controle da hemorragia digestiva em pacientes com cirrose hepática ${ }^{1,2}$. No entanto, sua indicação foi restringida em conseqüência de inúmeras complicações pósoperatórias. As principais são atrofia do parênquima hepático, transtornos no metabolismo de carboidratos, lipídios e proteínas, encefalopatia porto-sistêmica e diminuição da capacidade de regeneração hepáti$\mathrm{ca}^{3-7}$.

A atrofia do parênquima hepático pode ser devida à redução da pressão portal ${ }^{8}$ ou ao desvio do fluxo portal, com consequiente perda dos fatores hepatotróficos ${ }^{9}$. A encefalopatia hepática resulta, entre outros fatores, dos elevados níveis de amônia que têm sua metabolização hepática reduzida. Ela é tanto mais grave quanto mais intensa for a lesão prévia do fígado. Elevada no sangue, ela é tóxica para o cérebro ${ }^{2,5,10}$.

1. Professor Adjunto do Departamento de Medicina da UFS.

2. Professor Titular do Departamento de Cirurgia e Anatomia da Faculdade de Medicina de Ribeirão Preto da USP.

3. Cirurgião do Hospital Evangélico de Londrina.

4. Professor Associado do Departamento de Clínica Médica da Faculdade de Medicina de Ribeirão Preto da USP.

5. Acadêmico de Medicina da UFS.

Recebido em 12/08/2002

Aceito para publicação em 17/09/2002

Trabalho realizado na Faculdade de Medicina de Ribeirão Preto da Universidade de São Paulo. 
Com este trabalho, visa-se estudar os efeitos da anastomose porto-cava sobre a função hepática em cães.

O presente trabalho foi realizado de acordo com as recomendações da Declaração de Helsinque e com as Normas Internacionais de Proteção aos Animais.

\section{MÉTODO}

Foram utilizados 20 cães adultos, mestiços, do sexo masculino, pesando entre 13 e $20 \mathrm{~kg}$, provenientes do Biotério Central da Faculdade de Medicina de Ribeirão Preto da Universidade de São Paulo.

Eles foram divididos em dois grupos:

- Grupo I: constituído de 10 cães submetidos à hepatectomia parcial, em média de $28,7 \%$, mediante ressecção do lobo lateral esquerdo. Este grupo serviu como controle.

- Grupo II: constituído de 10 cães submetidos à hepatectomia parcial, em média de $28,7 \%$, mediante ressecção do lobo lateral esquerdo, e derivação porto-cava término-lateral.

No dia da cirurgia, o animal era mantido com água ad libitum. Nembutal sódico (etil-1 metil-butilbarbiturato sódico) na dose de $30 \mathrm{mg} / \mathrm{kg}$ de peso corpóreo foi aplicado endovenosamente e complementado quando se percebia superficialização da anestesia. A respiração foi controlada com respirador automático e cânula traqueal.

Após tricotomia e antissepsia da região abdominal anterior, realizou-se laparotomia com incisão mediana longitudinal xifo-umbilical. Posteriormente, ressecou-se, nos dois grupos, o lobo lateral esquerdo depois de dissecção adequada dos ligamentos e do hilo hepático. No Grupo II, além do que foi descrito, foi feita anastomose porto-cava término-lateral. Para tanto, a veia cava inferior foi dissecada desde a veia renal direita até o segmento retro-hepático. Os pequenos vasos lombares foram ligados. A veia porta foi dissecada desde a esplênica até sua bifurcação. Após pinçamento de ambas as veias, a veia porta foi seccionada, com ligadura de seu coto distal, sendo o proximal anastomosado à cava inferior. Finalizado esse procedimento, a cavidade abdominal foi fechada mediante sutura de sua parede por planos.

No primeiro dia pós-operatório, os animais receberam dieta líquida e, a partir do segundo, alimentos sólidos foram liberados. Após 14 dias, os cães foram mantidos em jejum de 12 horas para colheita de sangue arterial e dosagem de amônia. Trinta dias depois da cirurgia, foram submetidos a novo jejum para retirada de sangue venoso e arterial. Posteriormente, os cães foram sacrificados com o uso de nembutal sódico até parada cárdio-respiratória.

Os parâmetros utilizados para análise da função hepática foram os seguintes:

1. Consumo de anestésico durante a cirurgia $(\mathrm{mg} / \mathrm{kg} / \mathrm{min})$ : foi observada a influência do desvio do sangue portal no metabolismo de nembutal sódico durante a realização do ato cirúrgico. Para isso, foram registrados o consumo de anestésico por animal, seu peso, o grupo e a duração da cirurgia em minutos.

2. Amônia (ng/dl): a determinação dos valores de amônia foi feita no período pré-operatório, no $15^{\circ}$ e no $30^{\circ}$ dia após a cirurgia. A colheita sangüínea foi feita depois de 12 horas de jejum e por punção percutânea da artéria femoral. Cinco mililitros de sangue foram colocados em tubo cônico com quatro gotas de EDTA sódico para imediata mensuração.

3. Aspartato aminotransferase (U/l): a dosagem de AST foi feita no período pré-operatório e 30 dias após a cirurgia.

4. Teste de tolerância à bromosulfaleína (\%): realizado no pré-operatório e no $30^{\circ}$ dia do pós-operatório. Após 12 horas de jejum, injetavam-se $5 \mathrm{mg}$ / $\mathrm{kg}$ peso de bromosulfaleína a 5\%. Colheu-se sangue nos tempos 0,5 e 45 minutos. Foi verificado o índice de retenção da substância.

5. Proteínas totais e albumina $(\mathrm{g} / \mathrm{dl})$ : foram dosadas no período pré-operatório e no $30^{\circ}$ dia pósoperatório.

6. Bilirrubinas totais e frações $(\mathrm{mg} / \mathrm{dl})$ : foram dosadas no pré-operatório e 30 dias após a cirurgia.

Para a análise estatística dos resultados que envolveram até duas observações, como pré e pósoperatório, utilizou-se o teste de Wilcoxon e nos que envolveram mais de duas observações, o teste de Friedman. Para as comparações de dois grupos diferentes de procedimentos, foi utilizado o teste de Mann-Whitney. O nível de significância considerado foi de 0,01 .

\section{RESULTADOS}

O consumo médio de nembutal sódico durante a realização da hepatectomia no Grupo I foi de $34,2 \pm 2,7 \mathrm{mg} / \mathrm{kg}$ peso do animal para uma duração média de $58 \pm 10,6$ minutos. No Grupo II, houve consumo de $32,4 \pm 3,9 \mathrm{mg} / \mathrm{kg}$ peso de animal com tempo cirúrgico médio de 183,5 $\pm 48,6$ minutos. Isto significa 
que o consumo médio por unidade de tempo foi de $0,59 \mathrm{mg} / \mathrm{kg}$ peso/min no grupo controle e $0,18 \mathrm{mg} / \mathrm{kg}$ $\mathrm{peso} / \mathrm{min}$ no grupo submetido à derivação porto-cava. Este dado foi estatisticamente significativo. Para o sacrifício, a dose usada no Grupo II correspondeu a dois terços da aplicada no Grupo I.

A amonemia no Grupo I não apresentou diferenças entre o período pré-operatório e o $15^{\circ}$ e o $30^{\circ}$ dias do pós-operatório. No Grupo II, os valores do pós-operatório apresentaram-se significativamente ele- vados em relação aos do pré-operatório. Neste grupo, a amonemia demonstrou valores estatisticamente superiores aos do Grupo I no período pós-operatório (Tabela 1).

Os dois grupos apresentaram valores de AST no período pós-operatório estatisticamente superiores ao pré-operatório (Tabelas 2 e 3). Além disso, após a cirurgia, a AST estava significativamente mais elevada no grupo submetido à anastomose porto-cava quando comparada ao grupo controle (Tabela 4).

Tabela 1 - Valores da amonemia em ambos os grupos.

\begin{tabular}{llcc}
\hline & Pré-operatório & Pós-operatório (15 dias) & Pós-operatório (30 dias) \\
\hline Grupo I & $46,3+/-10,2$ & $43+/-12,7$ & $47,7+/-16,4$ \\
Grupo II & $44,4+/-10,6$ & $178,9+/-47,4^{*}$ & $217,7+/-60,3^{*}$ \\
\hline
\end{tabular}

* p<0,001 vs. Pré-operatório e Grupo I.

Tabela 2 - Valores da função hepática no Grupo I.

\begin{tabular}{lccl}
\hline & Pré-operatório & Pós-operatório (30 dias) & Estatística \\
\hline AST & $12,6+/-1,4$ & $14,9+/-2,3$ & $\mathrm{p}<0,01$ \\
Bromosulfaleína & $7,8+/-1,9$ & $7,9+/-1,7$ & \\
Proteínas totais & $5,6+/-0,8$ & $5,7+/-0,5$ & \\
Albumina & $3,4+/-0,6$ & $3,3+/-0,5$ & \\
Bilirrubinas totais & $0,17+/-0,1$ & $0,17+/-0,09$ & \\
Bilirrubina indireta & $0,13+/-0,08$ & $0,13+/-0,08$ & \\
\hline
\end{tabular}

Tabela 3 - Valores da função hepática no Grupo II.

\begin{tabular}{lccl}
\hline & Pré-operatório & Pós-operatório (30 dias) & Estatística \\
\hline AST & $13+/-1,6$ & $29,1+/-7,6$ & $\mathrm{p}<0,005$ \\
Bromosulfaleína & $8,6+/-2,6$ & $23,5+/-6,3$ & $\mathrm{p}<0,005$ \\
Proteínas totais & $5,7+/-0,6$ & $4,3+/-0,6$ & $\mathrm{p}<0,005$ \\
Albumina & $3,1+/-0,4$ & $2+/-0,7$ & $\mathrm{p}<0,005$ \\
Bilirrubinas totais & $0,21+/-0,14$ & $0,51+/-0,21$ & $\mathrm{p}<0,005$ \\
Bilirrubina indireta & $0,17+/-0,09$ & $0,35+/-0,09$ & $\mathrm{p}<0,005$ \\
\hline
\end{tabular}

Tabela 4 - Valores da função hepática no pós-operatório (30 dias) comparativos entre os Grupos I e II.

\begin{tabular}{lccl}
\hline & Grupo I & Grupo II & Estatística \\
\hline AST & $14,9+/-2,3$ & $29,1+/-7,6$ & $\mathrm{p}<0,001$ \\
Bromosulfaleína & $7,9+/-1,7$ & $23,5+/-6,3$ & $\mathrm{p}<0,001$ \\
Proteínas totais & $5,7+/-0,5$ & $4,3+/-0,6$ & $\mathrm{p}<0,001$ \\
Albumina & $3,3+/-0,5$ & $2+/-0,7$ & $\mathrm{p}<0,001$ \\
Bilirrubinas totais & $0,17+/-0,09$ & $0,51+/-0,21$ & $\mathrm{p}<0,001$ \\
Bilirrubina indireta & $0,13+/-0,08$ & $0,35+/-0,09$ & $\mathrm{p}<0,001$ \\
\hline
\end{tabular}


No teste de tolerância à bromosulfaleína, o Grupo I não teve diferença entre os períodos de análise (Tabela 2). No Grupo II, a retenção dessa substância estava elevada no período pós-operatório em comparação ao pré-operatório e ao mesmo período do Grupo I (Tabelas 3 e 4).

Não houve diferença estatística entre os valores de proteínas totais no pré e pós-operatório no Grupo I (Tabela1). No grupo submetido à anastomose, os valores do pós-operatório estavam significativamente reduzidos em relação ao período anterior à cirurgia e ao mesmo período do Grupo I (Tabelas 3 e 4). Essa alteração deveu-se à redução dos valores da albumina.

A dosagem de bilirrubinas totais e frações mostrou não haver qualquer diferença estatisticamente significativa no grupo controle nos períodos analisados (Tabela 2). Já no grupo submetido à anastomose porto-cava, os níveis de bilirrubinas totais e indiretas estavam aumentados em relação ao período pré-operatório (Tabela 3). Quando comparados aos do pósoperatório do grupo controle, também se apresentaram estatisticamente elevados (Tabela 4).

\section{DISCUSSÃO}

A derivação do sangue portal para a veia cava inferior foi idealizada no final do século XIX como opção terapêutica para a descompressão do sistema porta em presença de hipertensão portal ${ }^{11}$. Entretanto, após a descoberta de várias complicações após a cirurgia, esse procedimento foi substituído pelas derivações espleno-renais proximal e distal, derivação porto-cava calibrada e pela derivação porto-sistêmica transjugular intra-hepática ${ }^{10,12}$.

Um desses efeitos negativos da anastomose porto-cava é sobre a função hepática ${ }^{6,7}$. No presente estudo, verificamos que a exclusão do fígado pelo desvio do sangue portal compromete o metabolismo do nembutal sódico, prolongando o tempo de ação deste anestésico durante a cirurgia.

Não foram encontrados trabalhos na literatura relacionando a anastomose porto-cava à ação do nembutal sódico. Os autores acreditam que seu efeito prolongado após esse procedimento se deva à redução do fluxo hepático total, mantendo quantidades de anestésico não inativadas na circulação. O consumo reduzido do nembutal por ocasião do sacrifício está associado provavelmente à presença da anastomose e à função hepática degradada.
A elevação dos níveis da amônia sanguínea nos animais submetidos à anastomose porto-cava no período pós-operatório reforça essas hipóteses. A elevação da amonemia foi relacionada com alteração da função hepática como resultado da incapacidade do fígado de eliminar a amônia ${ }^{13,14}$. Entretanto, pacientes esquistossomóticos compensados e com circulação colateral exuberante apresentavam valores de amônia sangüínea normais ou ligeiramente aumentados $^{15}$. Isso mostra que a circulação colateral portosistêmica extensa, mas com função hepática preservada, pode manter amonemia normal.

Os resultados obtidos nos animais com anastomose porto-cava sugerem que o desvio do sangue portal e a deterioração hepatocelular são os fatores mais importantes na determinação dos valores elevados de amônia.

Outro parâmetro para analisar a função hepática é a dosagem da aspartato aminotransferase (AST), que determina o nível de integridade das células do fígado. Valores muito altos sugerem necrose hepatocelular extensa.

Nos animais do Grupo I, os níveis pós-operatórios de AST estavam levemente elevados, o que é habitual após hepatectomias parciais em função do trauma cirúrgico ${ }^{16}$. No Grupo II, a elevação foi muito mais proeminente, significando lesão celular intensa.

O teste de tolerância à bromosulfaleína representa a capacidade do fígado de remover e excretar pela bile esta substância administrada endovenosamente. No grupo submetido à anastomose porto-cava, a retenção média no pósoperatório estava muito elevada. Esses dados foram também observados por Lecompte ${ }^{17}$.

A remoção da bromosulfaleína pelo fígado depende do fluxo sangüíneo hepático total. Após anastomose porto-cava, parece que sua retenção está diretamente relacionada com o grau de comprometimento hepatocelular.

Alguns trabalhos relatam redução das proteínas totais após anastomose porto-cava ${ }^{18,19}$. Os resultados encontrados estão de acordo com os achados da literatura. A queda do nível protéico total foi associada à diminuição da albumina sérica. Foi sugerido que os aminoácidos absorvidos no intestino e derivados para a circulação sistêmica poderiam não ser aproveitados pelo fígado ${ }^{18,19}$.

Os valores médios das bilirrubinas totais do plasma aumentaram após derivação do sangue portal de maneira significativa às custas da fração indireta. 
A hiperbilirrubinemia após anastomose porto-cava parece ser decorrente da hemólise sangüínea por ação de substâncias do sangue portal na circulação sistêmica sobre os eritrócitos, tornando-os mais susceptíveis à ação do baço ${ }^{20}$.

Conclui-se que a anastomose porto-cava, associada à hepatectomia parcial, em cães causa: com- prometimento do metabolismo hepático de nembutal sódico durante a realização da cirurgia, prolongando seu tempo de ação; deterioração da função hepática, traduzida por elevação da amônia sangüínea, da aspartato aminotransferase, das bilirrubinas totais, e pela redução das proteínas totais e albumina plasmáticas.

\begin{abstract}
Background: The aim of this study was to assess the effect of portocaval shunt on liver function in dogs. Methods: Twenty animals were divided into two groups: Group I was submitted to $28.7 \%$ partial hepatectomy and Group II underwent partial hepatectomy associated with portocaval shunt. Data analyzed were the amount of anesthetic used during the surgical procedure, pre and post-operative (15 and 30 days later) ammonia levels, AST, total bilirubins and fractions, total proteins, albumin and the bromsulphalein tolerance test, all measured preoperatively and 30 days after surgery. Results: The anesthetic levels used were statistically lower in Group I. In Group II, only AST levels were higher post-operatively than preoperatively. On the other hand, Group II post-operative data were statistically higher when compared to preoperative and Group I values, except for total proteins and albumin levels, which were statistically lower. Conclusions: It is concluded that portocaval shunt induces liver dysfunction, which has been disclosed by high ammonia levels and changes in liver function tests.
\end{abstract}

Key Words: Portacaval shunt; surgical; Hepatectomy; Liver; Models, animal.

\section{REFERÊNCIAS}

1. Child III CG - Eck's fistula. Surg Gynecol Obstet, 1953, 96:375.

2. Franco D, Castaing D, Bismuth $\mathrm{H}$ - Conséquences métaboliques de dérivations portales expérimentales. Pathol Biol, 1979, 27(4):192-196.

3. Resnick RH, Iber FL, Ishihara AM, et al. - A controlled study of the therapeutic portocaval shunt. Gastroenterology, 1974, 67(5):843-857.

4. Pezzarossa A, Contini S, Bonora E, et al. - Glucose tolerance after portacaval shunt in liver cirrhosis. Diabete Metab , 1986, 12(4):197-202.

5. Meyer HP, Legemate DA, van den Brom W, et al. Improvement of chronic hepatic encephalopathy in dogs by the benzodiazepine-receptor partial inverse agonist sarmazenil, but not by the antagonist flumazenil. Metab Brain Dis, 1998, 13(3):241-251.

6. Awad SS, Hemmila MR, Soldes OS, et al. - A novel stable reproducible model of hepatic failure in canines. J Surg Res, 2000, 94(2):167-171.

7. Ennker IC, Mei M, NagelE, et al. - Changes in liver function and morphology after various portocaval bypass operations. Langenbecks Arch Chir, 1992, 377(3):144-151.

8. Sato Y, Tsukada K, Tanaka K et al. - New aspects in the liver regeneration following partial hepatectomy. Nippon Geka Gakkai Zasshi, 1997, 98(8):706-712.
9. Richardson PD, Withrington PG - Physiological regulation of the hepatic circulation. Annu Rev Physiol, 1982, 44:57-69.

10. Antunes RA, Duval-Araujo I - Evolução das varizes esofagogástricas após anastomose esplenorrenal proximal versus esplenorrenal distal. Rev Col Bras Cir, 2000, 27(2):102-108.

11. Eck NV - Kvoprosu o perevyaskie vorotnois veni. Predvaritennoye soobshtshjenys (Ligature of the portal vein). Voen Med J, 1877, 130:1.

12. Zacks SL, Sandler RS, Biddle AK et al. - Decisionanalysis of transjugular intrahepatic portosystemic shunt versus distal splenorenal shunt for portal hypertension. Hepatology, 1999, 29(5):1399-1405.

13. Schliess F, Häussinger D - Hepatic encephalopathy and nitric oxide. J Hepatol, 2001, 34(4):610-612.

14. Porcheron J, Balique JG - Physiopathologie et traitement chirurgical de l'encéphalopathie hepatique après anastomose porto-cave. Ann Gastroenterol Hepatol, 1995, 31(5):287-294.

15. Warren KS, Rebouças G, Baptista AG - Ammonia metabolism and hepatic coma in hepatosplenic schistosomiasis. Ann Intern Med, 1965, 62:1113.

16. Castro e Silva Jr O, Zucoloto S, Menegazzo LA, et al. Laser enhancement in hepatic regeneration for partially hepatectomized rats. Lasers Surg Med, 2001, 29(1): 73-77. 
17. Lecompte Y, Franco D, Martin ED, et al. - Liver arterialization with portacaval shunt in the cirrhotic rat. Surgery, 1974, 75(2):161-168.

18. Goffi FS. Alguns aspectos metabólicos experimentais das derivações porto-cavas simples ou associadas à derivação aorto-portal. Dissertação(Livre Docência). São Paulo. Universidade de São Paulo, 1955.

19. Svec MH, Freeman S - Effect of the impaired hepatic circulation on plasma free aminoacids of dogs. Am J Physiol, 1949,159:357.
20. Silva LC. Estudo da hiperbilirrubinemia pós-anastomose porto-cava em pacientes com esquistossomose hépatoesplênica e cirrose hepática. Dissertação (Doutorado). São Paulo. Universidade de São Paulo, 1961.

Endereço para correspondência:

Valdinaldo Aragão de Melo

Rua Álvaro Brito, 14, apt 301, Praia 13 de Julho

CEP 49020-400 -Aracaju-SE

E-mail: vamelo@infonet.com.br

Tel: 55-79-2462217/Fax: 55-79-2462857 